\title{
A thermostable, chromatographically purified Ebola nano-VLP vaccine
}

\author{
John H Carra ${ }^{1 *}$, Karen A O Martins ${ }^{1}$, Rowena D Schokman ${ }^{1}$, Camenzind G Robinson ${ }^{2,3}$, Jesse T Steffens ${ }^{1}$ \\ and Sina Bavari ${ }^{1}$
}

\begin{abstract}
Background: Filovirus virus-like particles (VLP) are strong immunogens with the potential for development into a safe, non-infectious vaccine. However, the large size and filamentous structure of this virus has heretofore made production of such a vaccine difficult. Herein, we present new assays and a purification procedure to yield a better characterized and more stable product.
\end{abstract}

Methods: Sonication of VLP was used to produce smaller "nano-VLP", which were purified by membrane chromatography. The sizes and lengths of VLP particles were analyzed using electron microscopy and an assay based on transient occlusion of a nanopore. Using conformationally-sensitive antibodies, we developed an in vitro assay for measuring GP conformational integrity in the context of VLP, and used it to profile thermal stability.

Results: We developed a new procedure for rapid isolation of Ebola VLP using membrane chromatography that yields a filterable and immunogenic product. Disruption of VLP filaments by sonication followed by filtration produced smaller particles of more uniform size, having a mean diameter close to $230 \mathrm{~nm}$. These reduced-size VLP retained GP conformation and were protective against mouse-adapted Ebola challenge in mice. The "nano-VLP" consists of GP-coated particles in a mixture of morphologies including circular, branched, "6"-shaped, and filamentous ones up to $\sim 1,500 \mathrm{~nm}$ in length. Lyophilization conferred a high level of thermostability on the nano-VLP. Unlike Ebola VLP in solution, which underwent denaturation of GP upon moderate heating, the lyophilized nano-VLP can withstand at least $1 \mathrm{~h}$ at $75^{\circ} \mathrm{C}$, while retaining conformational integrity of GP and the ability to confer protective immunity in a mouse model.

Conclusions: We showed that Ebola virus-like particles can be reduced in size to a more amenable range for manipulation, and that these smaller particles retained their temperature stability, the structure of the GP antigen, and the ability to stimulate a protective immune response in mice. We developed a new purification scheme for "nano-VLP" that is more easily scaled up and filterable. The product could also be made thermostable by lyophilization, which is highly significant for vaccines used in tropical countries without a reliable "cold-chain" of refrigeration.

Keywords: Filovirus, vaccine, Ebola, Virus-like particle, Immunogenicity, Thermostability

\section{Background}

The filoviruses Ebola and Marburg are enveloped viruses causing lethal, hemorrhagic disease in humans and non-human primates [1]. The virions exist in a mixture of morphologies, including " 6 "-shaped and

\footnotetext{
*Correspondence: john.h.carra.civ@mail.mil

${ }^{1}$ Molecular and Translational Sciences, United States Army Medical Research Institute of Infectious Diseases, Fort Detrick, MD 21702-9211, USA

Full list of author information is available at the end of the article
}

filamentous particles. The filaments are $80-100 \mathrm{~nm}$ in width and can be several microns long [2]. The surface of the virions is covered in trimeric spikes of the glycoprotein (GP), while the VP40 protein forms a structural matrix underlying the viral membrane. Formation of virus-like particles (VLP) with shapes similar to authentic filoviruses can be induced by transfection into human or insect cell lines of the genes for GP and VP40 alone [3-6]. The five other viral proteins are not essential for production of virus-like particles, although 
some efforts have also included the nucleocapsid protein NP.

VLP are useful as laboratory reagents for the exploration of filovirus biology, and they are promising candidates for vaccines to protect humans against natural or deliberate exposure to these viruses [7]. Non-human primates have been successfully immunized against Ebola with VLP plus adjuvant, with at least two doses needed for full protection, while one conferred partial protection $[8,9]$. Filovirus VLP are more effective than soluble GP proteins at stimulating the immune system [10]. The presentation of GP trimers in a repetitive array likely contributes to their potency by increasing interactions with receptors on $B$ cells and antigen-presenting cells [2, 11]. However, unlike VLP of some other types of viruses, which may consist only of smaller, spherical and nonenveloped proteinaceous particles that can be reassembled in vitro from isolated subunits, filovirus VLP can be several microns in length and are enveloped. These characteristics present difficult problems in purification, sterilization and analytical methods. Development of the filovirus VLP as vaccines for humans hence has been limited by the methods used in production, which rely upon sucrose gradient ultracentrifugation for purification and gamma-irradiation for sterilization. Production of the VLP by transient transfection also introduces high costs to supply the doses used in NHP experiments (typically $50-250 \mu \mathrm{g} \mathrm{GP}$ ), therefore more efficient means of expression are desirable.

The influence of the large size of the filaments on stimulation of the immune response is not yet clear. The optimal size and shape of nanoparticle vaccines is an important factor in their design and a subject of current interest (reviewed in [12-14]). For example, Manolova et al. [15] studied the effect of particle size on antigen uptake by dendritic cells and found that polystyrene beads of $\leq 200 \mathrm{~nm}$ were able to drain rapidly to lymph nodes, where they were taken up by lymph node-resident dendritic cells and macrophages. Beads $\geq 500 \mathrm{~nm}$ could not directly enter the lymphatic system, and were taken up more slowly by a different population of dendritic cells at the site of injection. Champion and Mitragotri [16] found that worm-like polystyrene particles were taken up by macrophages very poorly when compared to spherical particles. These results suggest that it may be advantageous to the immune response to reduce the length of filovirus VLP.

In this study, we examined how changes in particle size and GP conformation affect immunogenicity using a combination of mouse bioassays, electron microscopy (EM), antibody-based probes of GP, and a nanopore sizing method. We also demonstrate a rapid in vitro test for antigenic integrity that was correlated to in vivo potency, and confirm the functional significance of conformationally intact GP for the vaccine. We present results describing a new version of the Ebola VLP vaccine consisting of smaller particles that are more easily purified and can be filtered to reduce bioburden.

\section{Methods \\ VLP production and purification}

VLPs were produced at NCI and USAMRIID using a modification of the procedure described by Warfield et al. [3]. In brief, VLPs were created by transfecting HEK 293 cells with expression vectors containing the genes for GP and VP40 proteins. After a low-speed centrifugation to remove cells, VLP in the culture supernatant were centrifuged to a pellet using a Beckman JLA10.5 rotor at $10,000 \mathrm{rpm}(\sim 18,500 \times g)$. The pellet was resuspended in PBS and applied to a $10-60 \%$ sucrose gradient. The gradient was then spun at $174,000 \times g$ for $14 \mathrm{~h}$. The resulting band was removed from the gradient and washed twice in sterile PBS. The VLP were resuspended in PBS and stored at $4^{\circ} \mathrm{C}$, to be used in freeze/thaw studies. VLP were also produced under a contract at Paragon Bioservices, using a sucrose-gradient based method performed at a larger scale with a Wave bioreactor and HEK 293F suspension cells. These samples were stored frozen at $-80^{\circ} \mathrm{C}$.

The concentration of GP in the VLP was determined at Paragon by quantitative Western blotting with antibody $6 \mathrm{D} 8$, using recombinant soluble GP protein with a C-terminal His-tag in place of the transmembrane peptide as the standard. Subsequent measurement of GP concentrations of VLP samples were done by ELISA at USAMRIID and gave results within $10 \%$ of those found by Western blotting. GP was typically $20-30 \%$ of the total protein as measured by bicinchoninic acid assay. To measure GP concentration by ELISA, a standard curve was prepared by adhering recombinant soluble GP protein overnight to an ELISA plate (Immulon 2HB from Thermo Fisher \#3455) in carbonate buffer at $\mathrm{pH} 9.5$ (Additional file 1: Figure S1). The soluble GP protein was expressed in HEK293 c18 cells, and had the transmembrane region replaced by a His-tag for purification. It was quantitated by UV absorbance $\left(\mathrm{A}_{280} 1 \mathrm{mg} / \mathrm{mL}=1.30\right)$. GP on the ELISA plate was detected by probing with antibody 6D8 and an HRP-conjugated goat anti-mouse secondary antibody (Thermo Fisher \#31430). The absorbance at $408 \mathrm{~nm}$ was fit to a 4-parameter logistic equation using SigmaPlot.

\section{Sonication and filtration}

Sonication of VLP was done using a Branson Sonifier 250 with a $1 / 8$ inch tapered microtip. To prepare VLP samples for further study, $0.5 \mathrm{~mL}$ of VLP in PBS were sonicated for 3 sets of 3 pulses of $1 \mathrm{~s}$ duration, at $50 \%$ duty 
cycle with the output control at 5.5. Samples were chilled on ice after each set of pulses.

Filtration was done by passage through a $2.5 \mathrm{~cm}$ Supor syringe filter (Pall) of either $0.45 \mu \mathrm{m}$ or $0.8 / 0.2 \mu \mathrm{m}$ pore size.

\section{Electron microscopy}

Samples of VLP were adsorbed to formvar/carbon coated grids for electron microscopy and stained with PTA (phosphotungstic acid) or uranyl acetate. Samples were evaluated on a JEOL 1011 transmission electron microscope at $80 \mathrm{kV}$ and digital images were acquired using an Advanced Microscopy Techniques (Danvers, MA, USA) digital camera system.

\section{Particle sizing}

The particle size distribution of the samples was measured using an IZON qViro scanning ion occlusion sensing device. An IZON NP200A pore (nominal $200 \mathrm{~nm}$ diameter) was used, which was stretched until particles flowed freely. The voltage was $0.3-0.4 \mathrm{~V}$ and the pressure was varied up to $1.5 \mathrm{kPa}$. The sample introduced into the upper chamber contained $40 \mu \mathrm{L}$ of VLP with $0.4-0.8 \mu \mathrm{g} /$ $\mathrm{mL}$ [GP]. The buffer was PBS with $50 \mu \mathrm{g} / \mathrm{mL}$ Tween- 80 . Between 800 and 1,500 data points were collected for each experiment. The calibration standard was $217 \mathrm{~nm}$ polystyrene beads (SKP200B) diluted to $1 \times 10^{9}$ particles/mL concentration.

Particle concentrations were determined from the pressure dependence of the event rate [17]. The concentration of an unknown sample $\left(\mathrm{C}_{2}\right)$ was found from the slope of the pressure dependence of the sample's event rate $\left(\mathrm{g}_{2}\right)$, the calibration standard's slope $\left(\mathrm{g}_{1}\right)$, and the concentration of the standard $\left(\mathrm{C}_{1}\right)$ :

$$
C_{2}=\left(\frac{g_{2}}{g_{1}}\right) C_{1}
$$

\section{Conformational ELISA}

VLP samples were diluted in $0.2 \mathrm{M}$ sodium carbonate/ bicarbonate buffer at $\mathrm{pH} 9.5$ for coating of an Immulon $2 \mathrm{HB}$ plate (Thermo Fisher) overnight at $4^{\circ} \mathrm{C}$. After washing four times with $\mathrm{PBS} / 0.05 \%$ Tween-20, plates were blocked with $3 \%$ dry milk in PBS for $1.5 \mathrm{~h}$ at $37^{\circ} \mathrm{C}$. The wells were probed with antibody $6 \mathrm{D} 8,6 \mathrm{D} 3$, or $13 \mathrm{C} 6$ in $02 \%$ casein/PBS. 6D8 was used at $2.5 \mu \mathrm{g} / \mathrm{mL}, 6 \mathrm{D} 3$ at $1 \mu \mathrm{g} / \mathrm{mL}$, and $13 \mathrm{C} 6$ at $1.6 \mu \mathrm{g} / \mathrm{mL}$. HRP-labeled goat anti-mouse-Fc (Thermo) was the secondary antibody. Plates were developed with an ABTS peroxidase substrate (KPL), stopped with $1 \%$ SDS, and the absorbance read at $408 \mathrm{~nm}$.

\section{Nano-VLP purification}

Transfection of HEK 293 c18 cells (ATCC CRL-10852) with expression vectors for Ebola Zaire GP and VP40 was done using PEI as transfectant and $500 \mathrm{~mL}$ shaker flask cultures. After 3 days growth, the culture was centrifuged to remove cells $(1773 \times g$ for $15 \mathrm{~min})$. The supernatant was then centrifuged at higher speed to pellet the VLP $(18.6 \mathrm{~K} \times g$ for $2 \mathrm{~h})$. The pellet from each liter of cells was resuspended in $10 \mathrm{~mL}$ of $10 \mathrm{mM}$ sodium phosphate, $50 \mathrm{mM} \mathrm{NaCl}, \mathrm{pH} 7.4$ (buffer 1), and kept on ice. The resuspended pellet was sonicated to increase the fluidity of the sample and decrease the length of filamentous VLP, allowing for more efficient filtration.

Sonication of VLP was done using a Branson Sonifier 250 as described above. $10-12 \mathrm{~mL}$ of crude VLP in a $50 \mathrm{~mL}$ conical tube were sonicated for 4 sets of 3 pulses of $1 \mathrm{~s}$ duration, at $50 \%$ duty cycle with the output control at 5.5. Samples were chilled on ice after each set of pulses. After sonication, samples were diluted with an equal volume of buffer 1 . The sample was then filtered once through a $2.5 \mathrm{~cm}$ GF/D filter (Whatman glass microfiber), and then twice through GF/F filters. These steps removed a quantity of yellow colloidal material. $20 \mathrm{~mL}$ of the filtered sample was then run over a Sartorius Sartobind S-75 membrane chromatography disc, pre-equilibrated with buffer 1 on a GE Healthcare FPLC system. The VLP flowed through the S-75 disc. Bound contaminants were eluted for analysis only using a gradient to $2 \mathrm{M} \mathrm{NaCl}$. The flow rate was $1 \mathrm{~mL} / \mathrm{min}$ at a backpressure of $0.16 \mathrm{MPa}$. S-75 discs were not reused.

The flow-through of the S-75 disc was again sonicated for 3 sets of 3 pulses to reduce particle size. The sample was then centrifuged in $50 \mathrm{~mL}$ conical tubes for $2 \mathrm{~h}$ at $14.6 \mathrm{~K} \times g$ ) in a swinging bucket rotor. The pellet was resuspended in $2 \mathrm{~mL}$ of a sterile $0.5 \times$ PBS solution with $5 \%$ trehalose. The final filtration step to remove aggregates was done with a $2.5 \mathrm{~cm}$ Pall $0.45 \mu \mathrm{M}$ Supor filter. Bioburden was tested by plating on LB agar at $37^{\circ} \mathrm{C}$ and no growth was found. Use of a $0.2 \mu \mathrm{M}$ filter caused additional loss of the VLP and was not necessary to remove microbes for laboratory reagent purposes. Samples were then either stored frozen at $-80^{\circ} \mathrm{C}$, or lyophilized. Samples for SDS-PAGE were reduced and heated before loading on NuPage 4-12\% Bis-Tris gels (Life Technologies).

\section{Lyophilization}

For lyophilization, $262 \mu \mathrm{L}$ volume samples in $0.5 \times$ $\mathrm{PBS}+5 \%$ trehalose containing $60 \mu \mathrm{g}$ GP each were placed in $2 \mathrm{~mL}$ glass vials. $5 \%$ trehalose was included in the buffer as a protectant against stresses associated with freezing and dehydration. The samples were frozen on dry ice, and then placed on the shelf of a VirTis AdVantage ES freeze-dryer at $-20^{\circ} \mathrm{C}$ for drying in one stage. After $24 \mathrm{~h}$ exposure to vacuum (80 MT), the samples were reduced to a white powder. For stress-testing, the stoppered glass vial containing lyophilized VLP was 
placed in a $75^{\circ} \mathrm{C}$ block for $1 \mathrm{~h}$. A $26 \mathrm{G}$ needle was inserted to vent the cap during heating. All samples were resuspended in sterile water at the time of use.

\section{In vivo efficacy}

VLP were diluted in sterile saline for intramuscular administration. When the adjuvant poly-ICLC was used, it was diluted with the VLP in sterile saline and co-administered. Lyophilized VLP were reconstituted to approximately $500 \mu \mathrm{g} / \mathrm{ml}$ in sterile water prior to dilution in sterile saline. For all vaccination studies, female C57BL/6 mice (age 8-10 weeks) were vaccinated intramuscularly two times with $100 \mu$ l of volume, with 3 weeks between vaccinations. Two weeks after the final vaccination, peripheral blood was collected from vaccinated mice and antibody titers were measured using an IgG ELISA. Four weeks after the final vaccination, mice were challenged via the intraperitoneal (IP) route with $1,000 \mathrm{pfu}$ of mouse adapted (ma)-EBOV [18]. Research was conducted under an IACUC approved protocol in compliance with the Animal Welfare Act, PHS Policy, and other Federal statutes and regulations relating to animals and experiments involving animals. The facility where this research was conducted, USAMRIID, is accredited by the Association for Assessment and Accreditation of Laboratory Animal Care International, and it adheres to principles stated in the 8th Edition of the Guide for the Care and Use of Laboratory Animals, National Research Council, 2011.

\section{Anti-glycoprotein ELISA}

Anti-glycoprotein antibody titers were determined by ELISA. $2 \mu \mathrm{g} / \mathrm{mL}$ of recombinant Ebola virus glycoprotein was incubated in a flat bottom 96 well plate overnight. Glycoprotein with a C-terminal His-tag and lacking the transmembrane was expressed in HEK 293 c18 cells and purified by IMAC. Plates were incubated with blocking buffer (5\% milk, $0.05 \%$ Tween in PBS) for $2 \mathrm{~h}$, and then serum samples were added to plates. Samples were diluted by half log dilutions ranging from 2 to 5.5 logs. After $2 \mathrm{~h}$, plates were washed with PBS $+0.05 \%$ Tween and goat anti-mouse IgG-HRP secondary antibody was added at a $0.6 \mu \mathrm{g} / \mathrm{mL}$. One hour later, plates were washed and exposed using Sure Blue TMB 1-component substrate and stop solution (KPL), and the absorbance at $450 \mathrm{~nm}$ was recorded. Serum from unvaccinated animals was used to establish background and titers were defined as the serum dilution resulting in an absorbance greater than 0.2 , where background was universally less than 0.2 . Serum from animals previously determined to contain anti-glycoprotein antibody was included in each assay to serve as a positive control.

\section{Results}

Impact of sonication and filtration on the size distribution of VLP

As seen in earlier analyses [19], electron microscopy revealed that the Ebola Zaire VLP samples contained long filaments $(>1 \mu \mathrm{m})$ with bulbous regions that resemble Ebola virions, spherical particles similar to the head region of the virus, and some large irregular objects that might be cellular debris (Figure 1a). Sonication of the VLP was optimized by varying the number of applied pulses until conditions were found that yielded fragments of up to $\sim 400 \mathrm{~nm}$ length (Figure 1b) Sonication for a total of nine pulses was adequate to fragment the VLP,
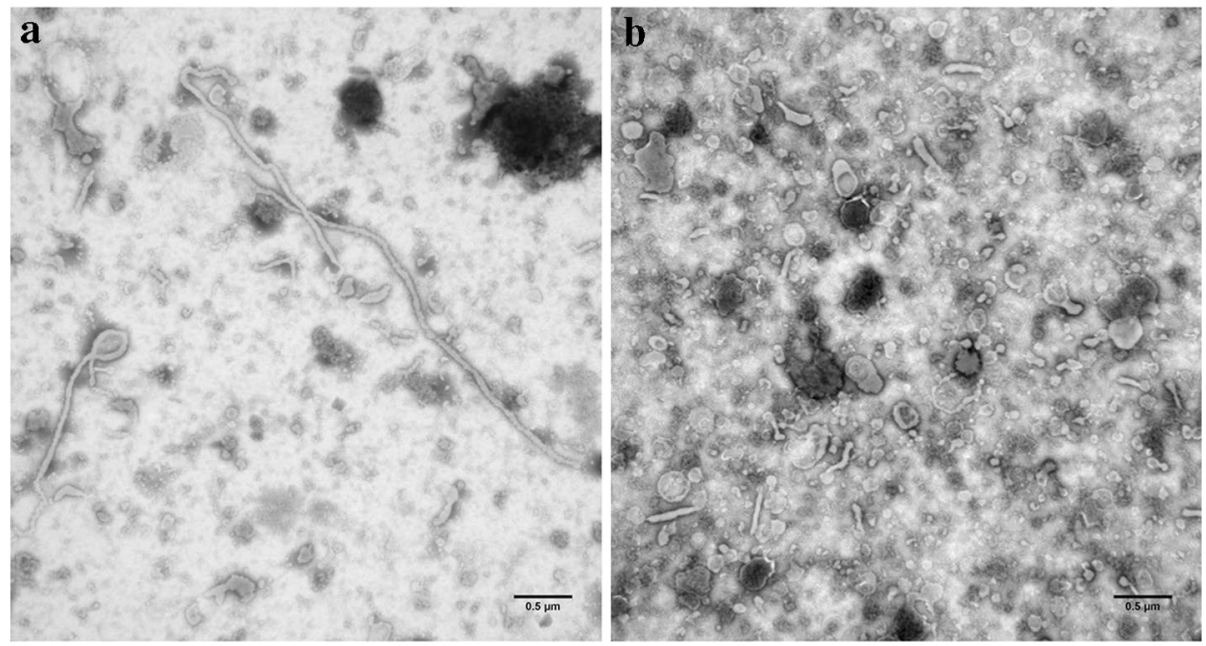

Figure 1 Electron micrographs of VLP before and after sonication. Bar is $0.5 \mu \mathrm{m}$. a Intact VLP. b Sonicated VLP. 
but more extensive disruption for a total of 30 pulses resulted in substantial loss of the integrity of the VLP membrane. Filtration of the sonicated samples through either a $0.45 \mu \mathrm{m}$ or $0.8 / 0.2 \mu \mathrm{m}$ cutoff syringe filter yielded both spherical particles and fragments of filaments, and effectively removed the larger particles and aggregates. Sonication of VLP improved the yield of GP through a $0.8 / 0.2 \mu \mathrm{m}$ filter from 10 to $50 \%$, and through a $0.45 \mu \mathrm{m}$ filter from 28 to $63 \%$.

The size distribution of the VLP samples was analyzed by Scanning Ion Occlusion Sensing (SIOS). In this method, particles in the sample are forced through a pore of adjustable size by an applied pressure and an electroosmotic potential. As particles pass through the pore, a change in current due to pore blockage is measured as a function of time. The amplitude of the decrease in current is proportional to the degree to which the pore is blocked, while the duration of the blockade event is the time required for the particle to transit the pore.
One advantage of this method lies in the characterization of heterogeneous samples containing particles of different sizes and shapes, which may be detected as individual blockade events rather than averaged over the whole population.

SIOS analysis of the undisrupted VLP yielded a bifurcated plot of the blockade event duration in ms (FWHM: full width at half maximum) vs. blockade height in $\mathrm{nA}$ (Figure 2a). The events of lesser height and longer duration in the VLP sample are consistent with the transit of narrow, elongated filamentous particles through the pore. VLP filaments, which are $70-85 \mathrm{~nm}$ wide and up to $4 \mu \mathrm{m}$ in length, may be expected to block the pore only partially, while taking a relatively long period of time to transit. In comparison, the spherical $217 \mathrm{~nm}$ polystyrene beads used for calibration showed a tight cluster of blockade events of less than $2 \mathrm{nA}$ magnitude and $0.2 \mathrm{~ms}$ duration. Disruption of the VLP by sonication (Table 1 ) resulted in the loss of most events with greater blockade amplitudes $(>2 \mathrm{nA})$
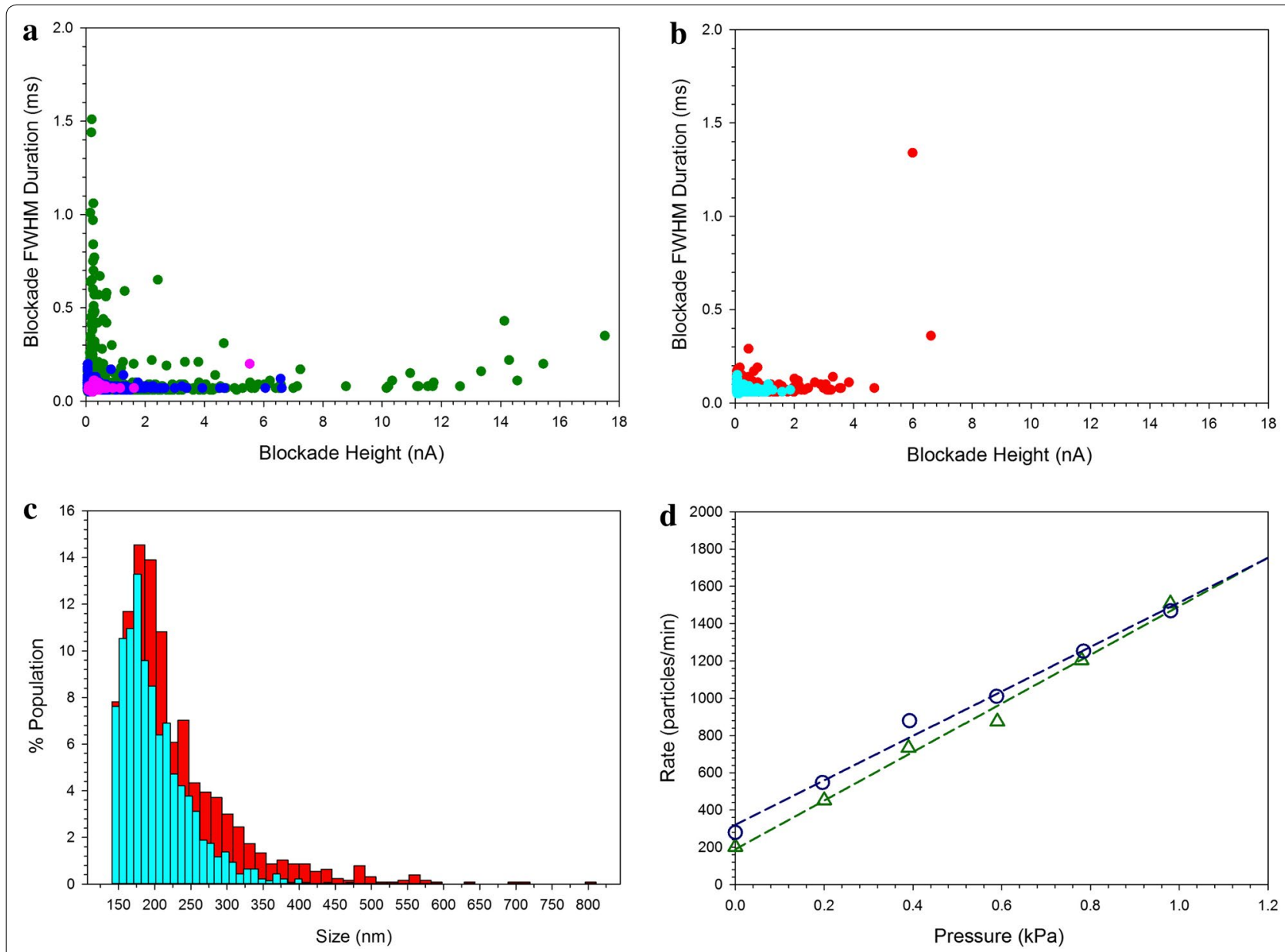

Figure 2 Nanopore measurements. a Intact VLP (green) sonicated VLP (blue) and $217 \mathrm{~nm}$ polystyrene beads (pink). b VLP after sonication and passage through a $0.45 \mu \mathrm{m}$ (red) or 0.8/0.2 $\mu \mathrm{m}$ (cyan) filter. c The calculated particle size distribution of filtered VLP samples after calibration using the polystyrene beads. $\mathbf{d}$ Pressure dependence of the particle flow rate. Calibration beads (green triangles), sonicated and filtered (0.45 $\mu \mathrm{m}) \mathrm{VLP}(\mathrm{blue}$ circles). $R^{2}$ was 0.99 for both linear regressions. 
Table 1 Nanopore analysis of VLP

\begin{tabular}{lll}
\hline Sample & \% FWHM $>\mathbf{0 . 2} \mathbf{~ m s}$ & \% Height $>\mathbf{2 ~} \mathbf{n A}$ \\
\hline Undisrupted & 6.7 & 6.2 \\
Sonicated & 0.1 & 1.9 \\
Sonicated and filtered $0.45 \mu \mathrm{m}$ & 0.3 & 2.1 \\
Sonicated and filtered $0.8 / 0.2 \mu \mathrm{m}$ & 0 & 0 \\
Incubated $37^{\circ} \mathrm{C} 24 \mathrm{~h}$ & 2.7 & 11 \\
Incubated $37^{\circ} \mathrm{C}$ $96 \mathrm{~h}$ & 2.7 & 9.1 \\
\hline
\end{tabular}

and nearly all those of longer duration $(>0.2 \mathrm{~ms})$, consistent with the disruption of filaments observed in the EM. Passage of the sonicated VLP through a $0.8 / 0.2 \mu \mathrm{m}$ syringe filter removed the larger remaining particles (Figure 2b).

Figure $2 \mathrm{c}$ shows the calculated particle size distributions of the filtered samples, which were consistent with what was observed by EM. The mean particle size is normally calculated from SIOS data by calibration using beads of known size [20]. However, this analysis may not be appropriate when the sample contains a significant fraction of elongated, non-spherical particles. We therefore present mean particle sizes only for the sonicated samples (Table 1), which have a relatively narrow distribution of particle sizes and shapes. The smaller particles of less than $150 \mathrm{~nm}$ could not be simultaneously resolved in this nanopore measurement; however we have chosen to focus the particles $>150 \mathrm{~nm}$ that were identifiable as VLP or fragments of VLP.

SIOS can also be used to determine particle concentrations from the rate of observed events compared to a calibration standard of known concentration [17]. However, passage of intact VLP samples through the SIOS pore was frequently interrupted by blockages, presumably due to the larger aggregates present. These blockages did not affect the particle size measurements, which were determined from individual events. Experiments could be resumed by pipetting the sample up and down, but a consistent flow rate of particles through the pore could not be obtained. By removal of larger particles or aggregates from the sample, filtration allowed a smooth flow through the pore for more than $1 \mathrm{~min}$.

Measurement of the rate of events at various applied pressures (Figure 2d) was then done to allow calculation of the particle concentration from the relative slopes of the pressure dependence curves. For the filtered VLP sample shown, the concentration was $8.2 \pm 0.8 \times 10^{11}$ particles $/ \mathrm{mL}( \pm \mathrm{SE}, \mathrm{n}=3)$.

\section{Thermostability of GP in VLP}

GP only comprises approximately $20-30 \%$ of the total protein in VLP preparations, but it is the most significant component in terms of immunogenicity [6]. The conformational integrity of GP is hypothesized to be important for immunogenicity. We therefore sought to develop an ELISA method that would characterize specifically the conformation of GP in VLP preparations subjected to applied stress. In this approach, we compared the relative amount of binding of antibodies that recognize either linear or conformational epitopes. Denaturation of GP would be expected to result in loss of recognition by the conformationally-sensitive antibodies, while binding of the linear epitope antibody would be maintained.

Antibody 6D8 recognizes a linear epitope of GP (a.a. 389-405), while $13 \mathrm{C} 6$ and 6D3 are conformationallydependent [21, 22]. $13 \mathrm{C} 6$ is known to bind to the glycan cap [23]. All are non-competing. We anticipated that if GP were denatured by applied stress, binding by $6 \mathrm{D} 8$ should remain relatively constant, while binding by $6 \mathrm{D} 3$ and 13C6 should decrease.

We used the ELISA method to test the resistance of both untreated, filamentous VLP and sonicated VLP to accelerated degradation by thermal stress. VLP samples were incubated at elevated temperatures for the indicated time periods in Figure 3a, b. Under all conditions tested, there was no difference between the impacts of thermal stress on sonicated VLP as compared to intact VLP, indicating that fragmentation of the VLP did not affect the conformational stability of GP.

Incubation at $37^{\circ} \mathrm{C}$ for up to $96 \mathrm{~h}$ had no significant effect on the conformational integrity of GP, as judged by binding of the conformationally sensitive 6D3 and 13C6 antibodies. Binding of the control 6D8 was unchanged by incubation at the higher temperatures. At $50^{\circ} \mathrm{C}$ or $55^{\circ} \mathrm{C}$ for 24 or $96 \mathrm{~h}$, partial loss of 6D3 binding was observed, and after only $10 \mathrm{~min}$ at 65 or $75^{\circ} \mathrm{C}, 13 \mathrm{C} 6$ binding was also lost almost completely. The reason for the more rapid loss of 6D3 binding on heating is not yet clear, but could be due to partial denaturation of domains of the GP as temperature increased.

While incubation at $37^{\circ} \mathrm{C}$ for as long as $96 \mathrm{~h}$ did not result in denaturation of GP, the integrity of filaments was affected. After incubating a VLP sample for $24 \mathrm{~h}$ at 


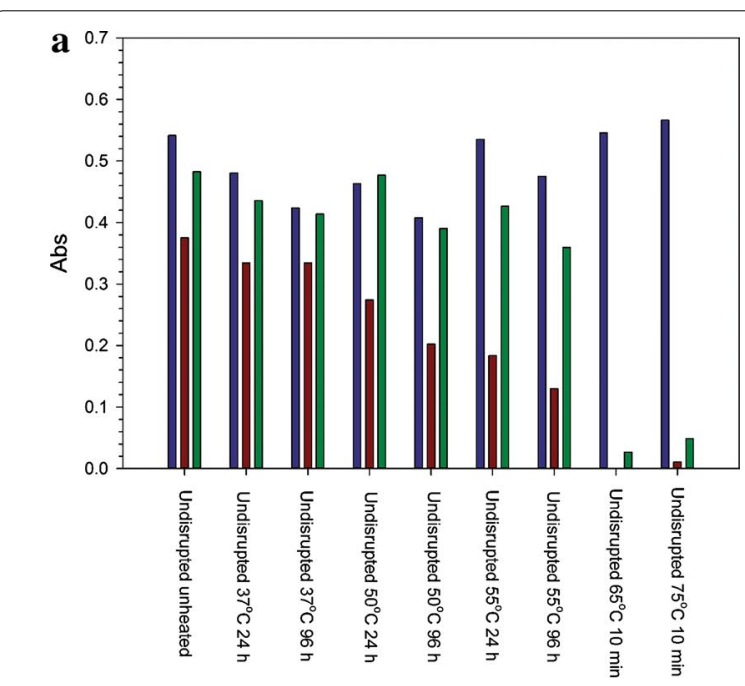

b
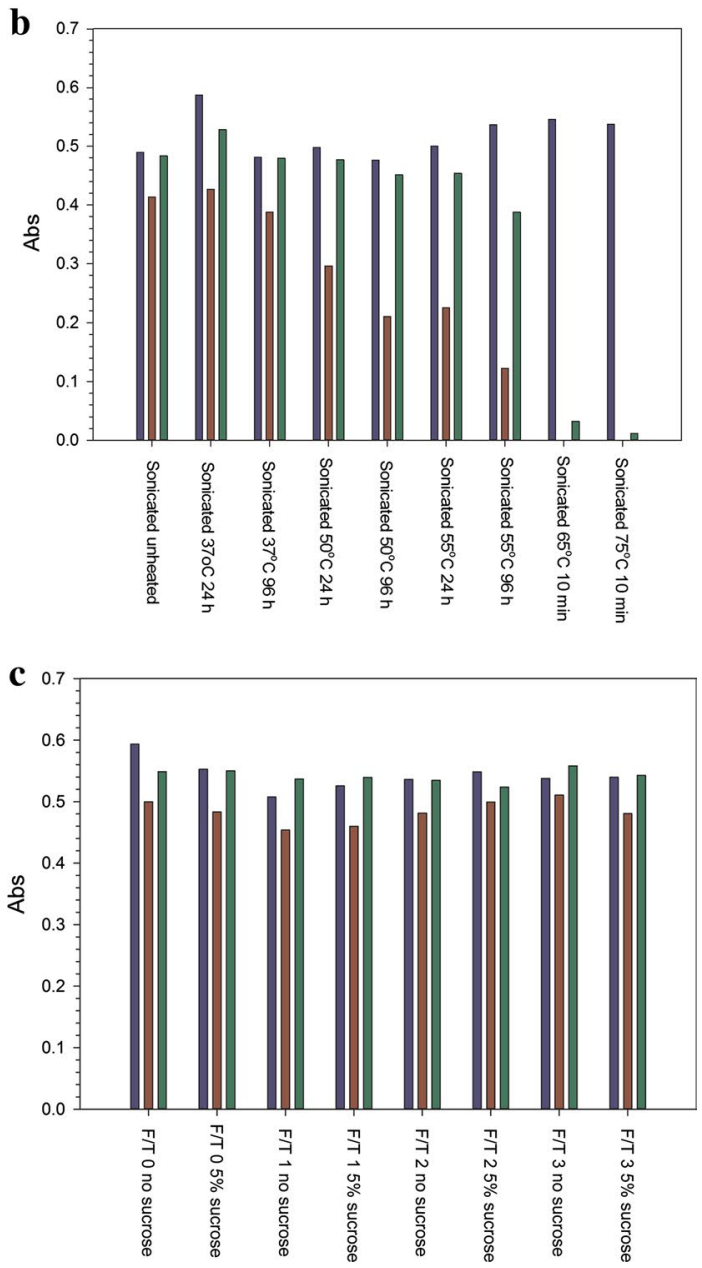

Figure 3 Accelerated degradation of VLP. a Undisrupted VLP incubated at elevated temperatures for the times indicated and probed by antibodies 6D8 (b/ue), 6D3 (red), or 13C6 (green). The absorbance at $408 \mathrm{~nm}$ is shown on the $y$-axis. b Sonicated VLP, same as part A. c Undisrupted VLP were subjected to repeated rounds of freeze/thawing in the presence or absence of $5 \%$ sucrose. $37^{\circ} \mathrm{C}$, we observed a decreased population of particles with long-duration pore transits (Table 1 and Additional file 1: Figure S2A). This result indicates that longer filaments are not stable to extended incubation at $37^{\circ} \mathrm{C}$, although GP conformation could be maintained even when filamentous structure was disrupted.

Having determined the sensitivity of GP in VLP to heating, we next evaluated the effects of repeated freeze/ thawing on VLP particle size and the GP conformation. The VLP preparation used for these studies was purified at USAMRIID and tested after having never been frozen, or having been subjected to 1-3 rounds of freeze/ thawing in PBS or PBS $+5 \%$ sucrose. VLP were thawed in a $37^{\circ} \mathrm{C}$ water bath and refrozen on dry ice. No significant change in GP conformation (Figure 3c) as a result of freeze/thawing was found. Electron microscopy and particle sizing measurements also found no significant change in size as a result of freeze/thawing (Additional file 1: Figure S2B).

\section{Immunopotency testing}

Based on our biochemical assessments, we had shown that optimized sonication can result in smaller, more homogenous VLP that expressed conformationally intact GP, while excessive heating of the VLP disrupted the GP conformation. To evaluate the relevance of these findings in terms of vaccine efficacy, we vaccinated C57BL/6 mice with VLP treated under the respective conditions and challenged them with ma-EBOV. Based on previous studies, we had shown that $10 \mu \mathrm{g}$ of VLP, based on GP content, was the minimum sufficient vaccine dose to reliably achieve $90-100 \%$ protection from challenge [24]. We therefore used this dose level as our baseline for analysis.

To evaluate the impacts of heating and sonication on VLP efficacy, we vaccinated animals with either $10 \mu \mathrm{g}$ or $2.5 \mu \mathrm{g}$ of VLP two times, on the schedule shown in Figure 4a. As shown in Figure 4 and Additional file 1: Table S1 (experiment \#1), VLP that were sonicated or heated at $37^{\circ} \mathrm{C}$ for $96 \mathrm{~h}$ provided comparable protection to filamentous control VLP that were not treated, suggesting that these conditions did not impact immunogenicity. In contrast, VLP that were heated at $75^{\circ} \mathrm{C}$ for $15 \mathrm{~min}$ did not provide protection from challenge, supporting a relationship between GP conformational integrity and immunogenicity. The $p$-values comparing survival of groups treated with control VLP or $75^{\circ} \mathrm{C}$ heated VLP confirmed the deleterious effect of high temperature, while the effects of sonication or $37^{\circ} \mathrm{C}$ incubation were not significant. Anti-GP antibody titers in animals vaccinated with VLP heated at $75^{\circ} \mathrm{C}$ were also significantly lower than the titers achieved in animals vaccinated with undisrupted VLP, sonicated VLP, or VLP heated at $37^{\circ} \mathrm{C}$, at both dose levels tested (Figure 4). 


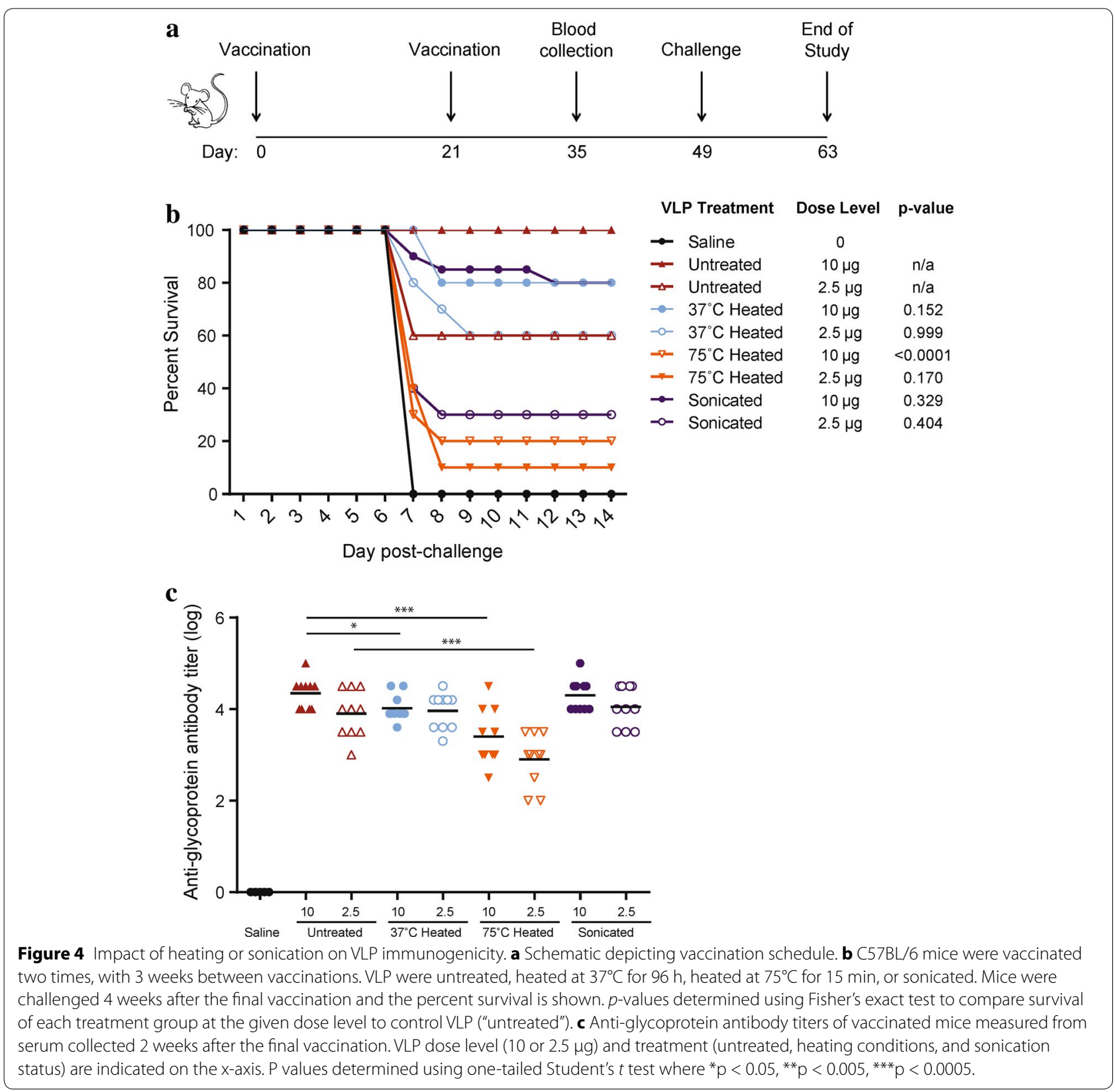

Considering that we had not observed $100 \%$ protection with the $10 \mu \mathrm{g}$ dose level of sonicated VLP, we chose to vaccinate animals with 10 or $20 \mu \mathrm{g}$ of VLP when comparing the impact of filtration on protection (Figure 5 and Additional file 1: Table S1, experiment \#2). Sonicated VLP that were filtered through a $0.45 \mu \mathrm{m}$ filter displayed comparable immunogenicity to those that were not filtered and to undisrupted VLP. VLP that were sonicated and then filtered with a $0.8 / 0.2 \mu \mathrm{m}$ cutoff had slightly lower efficacy, which was statistically significant ( $p$ value $<0.05$ ) at the $10 \mu \mathrm{g}$ dose, though antibody titers were comparable between all groups.

\section{Nano-VLP}

The results above suggested to us that difficulties in manufacture of full-length filamentous VLP might be overcome by a reduction in their size, without loss of potency. We then developed a procedure for purification of nanoVLP consisting of a combination of centrifugation, sonication, glass fiber filtration, and Sartobind S-75 membrane negative capture steps; with a final filtration for removal of aggregates and bioburden. The SDS-gel electrophoresis pattern of the nano-VLP product and a preparation made by the sucrose-gradient procedure [3] are shown in 

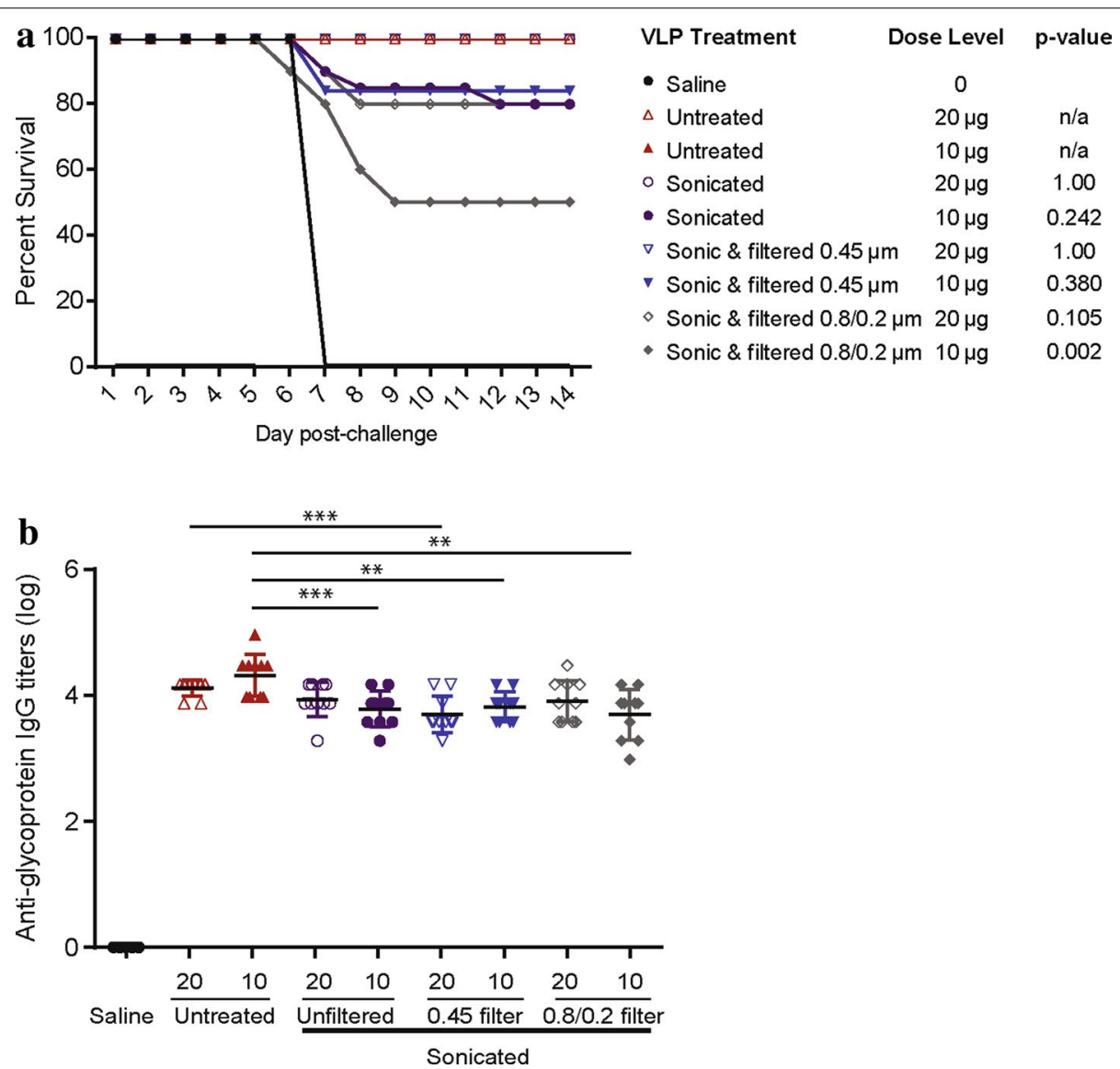

Figure 5 Impacts of sonication and filtration on VLP immunogenicity. a C57BL/6 mice were vaccinated two times, with 3 weeks between vaccinations, as in Figure 4a. VLP were untreated, sonicated, or sonicated and passed through either a $0.45 \mu \mathrm{m}$ or $0.8 / 0.2 \mu \mathrm{m}$ filter (indicated on $\mathrm{x}$-axis). The percent survival is shown. $p$-values determined using Fisher's exact test to compare survival of each treatment group at the given dose level to control VLP ("untreated"). b Anti-glycoprotein antibody titers of vaccinated mice measured from serum collected 2 weeks after the final vaccination. VLP dose level $\left(10\right.$ or $20 \mu \mathrm{g}$ ) is indicated on the x-axis. P values determined using one-tailed Student's $t$ test where ${ }^{*} p<0.05,{ }^{* *} p<0.005,{ }^{* * *} p<0.0005$.

Additional file 1: Figure S3. The protein bands appear very similar in migration and relative amounts. We also verified that the nano-VLP preparation possessed appropriate GP conformation by ELISA as done above (not shown). Measurement of the GP yield by ELISA with antibody 6D8 gave figures of $1.6-2.0 \mathrm{mg} / \mathrm{L}$ of cell culture, in comparison with $\sim 1 \mathrm{mg} / \mathrm{mL}$ for the sucrose gradient method. Both contained $20-30 \%$ GP when total protein was measured by BCA. A final $0.45 \mu \mathrm{m}$ filtration provided adequate bioburden removal for laboratory usage, yielding a product that showed no bacterial growth on plating. Filtration with a $0.8 / 0.2 \mu \mathrm{m}$ filter was possible but resulted in additional loss of product.

Transmission electron microscopy of the nano-VLP with PTA staining showed linear, branched, spherical and "6" shaped particles (Figure 6a). Linear filaments were as long as 1.5 microns, but most particles were shorter filaments or spheres of $\sim 200 \mathrm{~nm}$ diameter. Particle size was also examined using a qViro device (Figure $7 \mathrm{a}$ ). With the
nano-VLP sample, 7.1\% of observed events had a passage duration of $>0.2 \mathrm{~ms}$. These events may represent passage of the shorter filaments found in Figure 6a. Results from the qViro nanopore analysis appeared to be consistent with the EM data. The nano-VLP were not observed to possess lengths of several microns as is commonly found in sucrose-gradient purified VLP and authentic virions. The mean particle diameter was calculated to be $230 \mathrm{~nm}$ using a spherical bead standard; however, this method does not take into account the shape of the filament fragments. Although some of the fragments of filaments present were longer than the 0.45 micron pore size filter used in this preparation, their width was less than $100 \mathrm{~nm}$.

We tested lyophilization of the nano-VLP as a possible means to formulate for stable storage. Figure $6 \mathrm{~b}$, c show electron micrographs of the lyophilized nanoVLP, after resuspension in water. The filaments retained structure after lyophilization, although some shortening 


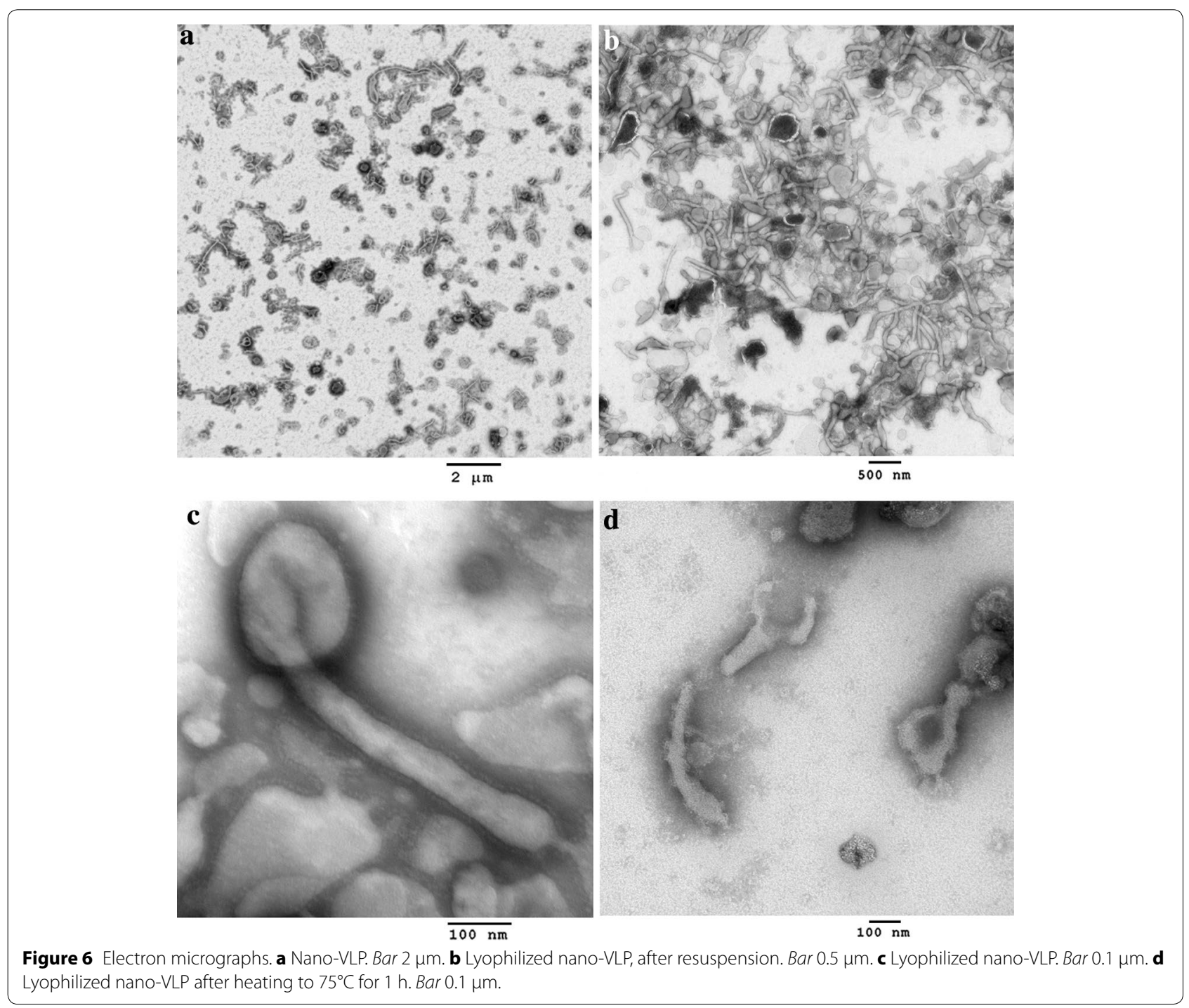

of filaments occurred, which was confirmed by nanopore analysis (Figure 7a). The calculated mean particle diameter of the lyophilized nano-VLP was $217 \mathrm{~nm}$. The GP layer coating the lyophilized nano-VLP was visualized by negative staining in Figure 6c, and was detected by immunogold-staining with antibody 6D8 (Figure S4). Retention of the folded conformation of GP in the nanoVLP after lyophilization was confirmed using ELISA (Figure $7 \mathrm{~b}$ ). Lyophilized VLP resuspended readily without the appearance of aggregation, and the particles flowed easily through the nanopore.

As described above, we observed that the GP of Ebola VLP underwent denaturation when heated in liquid suspension to $75^{\circ} \mathrm{C}$ for $15 \mathrm{~min}$, which was correlated with a nearly complete loss of protective capability in the mouse model. However, we found that lyophilized nano-VLP could be heated in the dry form before resuspension to $75^{\circ} \mathrm{C}$ for at least $1 \mathrm{~h}$, with little apparent loss of GP conformation as determined by conformational ELISA (Figure $7 \mathrm{~b}$ ). Electron micrographs of the heated, lyophilized nano-VLP (Figure 6d) showed that the filament fragments were relatively unchanged, although increased irregularities on the membrane surface were apparent.

\section{Efficacy as a vaccine}

The ability of the nano-VLP to confer protection from mouse-adapted Ebola challenge was tested in a mouse assay. Figure 8a shows results of an experiment in which mice were vaccinated with $5 \mu \mathrm{g}$ doses of various VLP preparations [GP content of VLP] in combination with $10 \mu \mathrm{g}$ poly-ICLC adjuvant. The VLP preparations that were tested are as follow: sucrose-gradient purified VLP, 

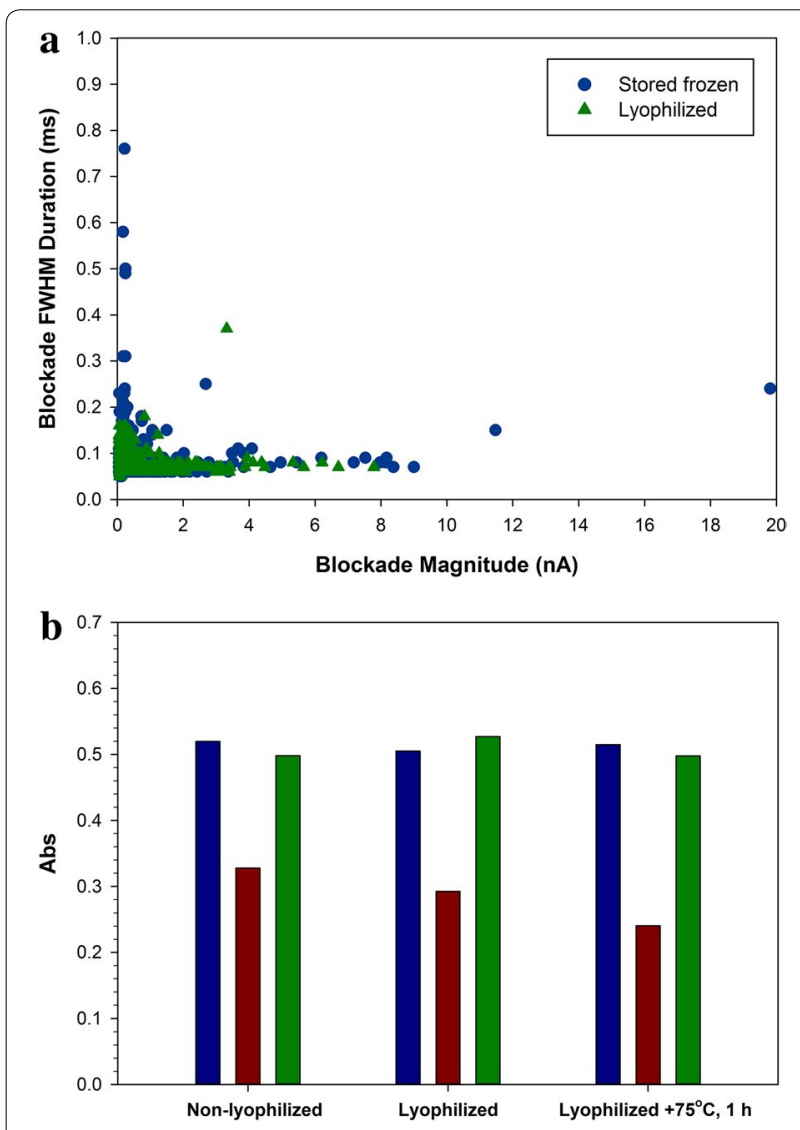

Figure 7 a Nanopore event duration (ordinate) and blockade magnitude (abscissa) of non-lyophilized (blue circles) and lyophilized (green triangles) nano-VLP. b ELISA to probe the conformational integrity of GP in nano-VLP that were not lyophilized, lyophilized, and lyophilized and heated to $75^{\circ} \mathrm{C}$ for 1 h. Blue bars linear epitope antibody $6 \mathrm{D} 8$, red bars conformational antibody 6D3, green bars conformational antibody $13 \mathrm{C} 6$.

which served as a bridging control to previous studies; nano-VLP that were stored frozen; nano-VLP that were lyophilized; and lyophilized nano-VLP that had been heated in the vial at $75^{\circ} \mathrm{C}$ for $1 \mathrm{~h}$ prior to resuspension. All $(10 / 10)$ animals vaccinated with adjuvant only died after challenge with mouse-adapted Ebola virus, while all in the VLP-vaccinated groups survived (Figure 8a). The anti-GP titers in the VLP-containing groups were uniformly high (Figure 8b).

As a more stringent test of immunogenicity, we performed an experiment without the use of adjuvant (Figure $8 \mathrm{c}, \mathrm{d}$ ). nano-VLP were administered at doses of 5 or $20 \mu \mathrm{g}$ GP content (Additional file 1: Table S2). For each group, $20 \mu \mathrm{g}$ conferred better protection than $5 \mu \mathrm{g}$. At the $20 \mu \mathrm{g}$ dosage, nano-VLP that had been stored frozen yielded 6/10 survival, while lyophilized nano-VLP gave $10 / 10$ survival and lyophilized/heated VLP gave $9 / 10$. For all of these groups except lyophilized nano-VLP at $5 \mu \mathrm{g}$, survival vs. saline control was statistically significant. However, differences in survival between the vaccine groups, including the filamentous VLP used in earlier studies, were not statistically significant. Anti-GP titers also showed a dose response, and titers for the heated, lyophilized VLP were significantly higher than titers for lyophilized nano-VLP or frozen nano-VLP at the $20 \mu \mathrm{g}$ dose level. The reason for this higher titer is not known.

\section{Discussion}

\section{VLP stability and GP conformation}

Vaccines that can withstand ambient temperatures for extended periods are highly desirable to avoid loss of potency if the cold chain is broken. Thermal stability studies on VLP indicated that the GP antigen can withstand moderately high temperature stress for an extended period. Incubation at $55^{\circ} \mathrm{C}$ for more than $24 \mathrm{~h}$ resulted in partial loss of conformation, while at $75^{\circ} \mathrm{C}$ denaturation occurred rapidly as measured by ELISA. No significant loss of GP conformation was observed with $96 \mathrm{~h}$ incubation at $37^{\circ} \mathrm{C}$, however. Loss of conformational integrity in the ELISA was correlated to loss of immunopotency in a mouse bioassay, demonstrating that the conformational ELISA method introduced herein can be used to predict rapidly the decreased potency of thermally stressed Ebola VLP vaccine samples. Structural studies of neutralizing antibodies to Ebola GP support the importance of GP conformation in antibody recognition [25].

Only one other study has examined filovirus VLP stability systematically, to our knowledge [26]. Those authors used biophysical methods on VLP derived from a baculovirus expression system, while we employed a human cell-based system and developed approaches to focus specifically on antigenic integrity. The light scattering and circular dichroism measurements of $\mathrm{Hu}$ et al. indicated that at neutral $\mathrm{pH}$ Ebola VLP's lost conformational integrity above $50-60^{\circ} \mathrm{C}$. Although the thermal transitions were broad, and global properties of the VLP were assayed rather than those of GP specifically, those results are consistent with ours.

\section{Particle size vs. immunogenicity}

Previous studies have found that particles greater $500 \mathrm{~nm}$ in size are processed more slowly by the immune system due to exclusion from direct drainage to lymph nodes [11]. This fact might suggest that large filamentous VLP would be less immunogenic than smaller VLP. However, we found no significant difference in potency between the filamentous and sonicated VLP using the mouse vaccination model. The roughly $230 \mathrm{~nm}$ average size of the sonicated VLP was large enough to provide the repeated antigen array necessary for strong stimulation of the immune response by GP [10]. Passage of the sonicated 


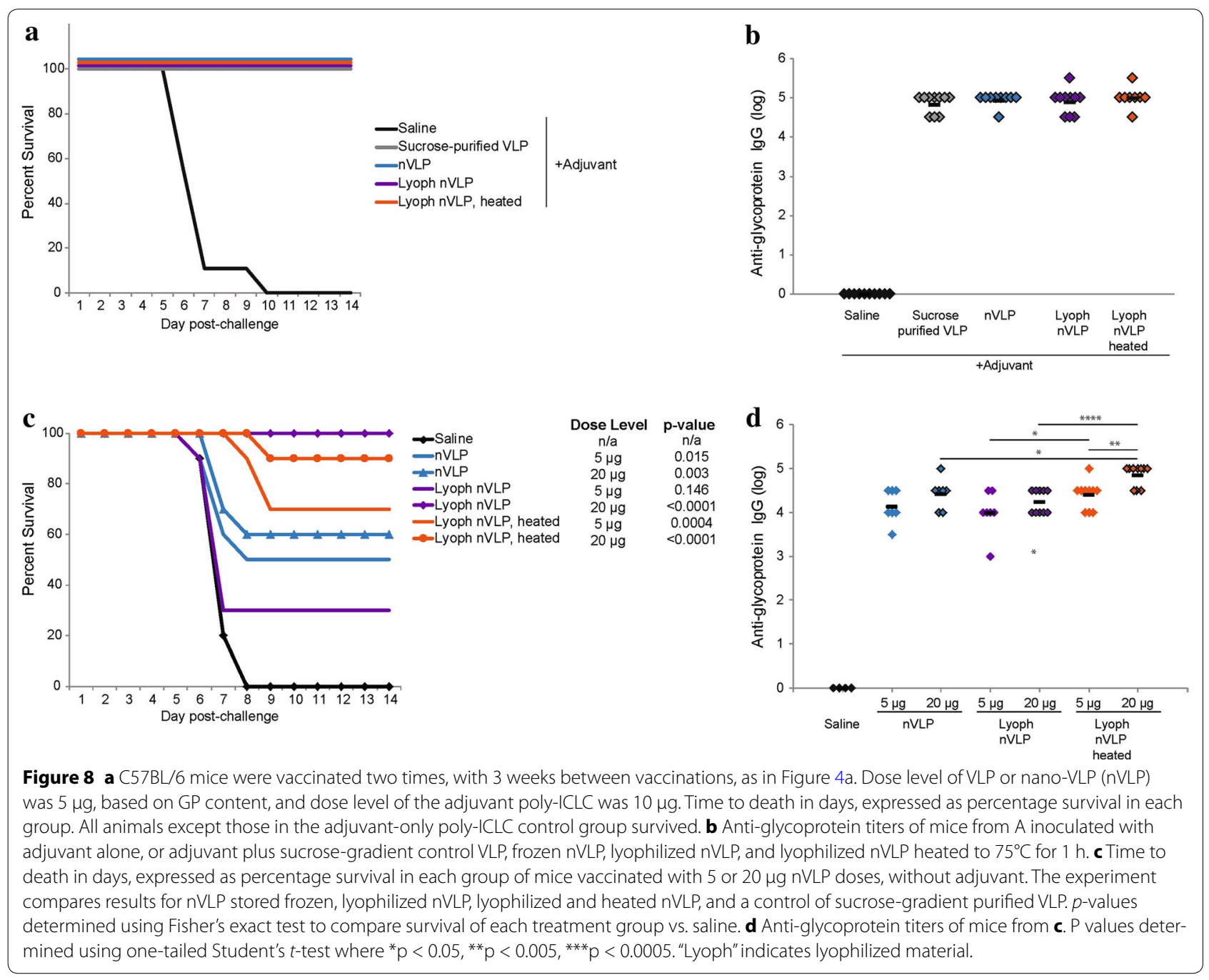

VLP through a $0.45 \mu \mathrm{m}$ filter did not appear to affect potency, but passage through a $0.8 / 0.2 \mu \mathrm{m}$ filter resulted in a lower survival rate after challenge. However, a statistically significant difference in potency of the more stringently filtered VLP was observed only at the $10 \mu \mathrm{g}$ dose (Additional file 1: Table S1).

To the extent that the mouse model is predictive, our results indicate that the presence of intact filaments is not essential to a VLP vaccine. The finding that reduction of particle size by sonication did not greatly change immunogenicity may be due at least in part to disruption of longer VLP filaments in vivo. We observed that extended incubation at $37^{\circ} \mathrm{C}$ resulted in shortening of filaments, as determined by nanopore sizing measurements. This suggests that VLP filaments will breakdown into pieces after injection into the body of an animal, with the result being that the large initial size of the VLP may not be an impediment to access to the lymphatic system.

\section{Nano-VLP and progress in vaccine development}

We have described a new process for purification of a filovirus VLP vaccine that is more rapid and easily scaled for manufacturing than the previous sucrose gradientbased method. The size of the nano-VLP was smaller than that of complete Ebola virions, with spherical particles of roughly $230 \mathrm{~nm}$ diameter, and filaments of around $500 \mathrm{~nm}$ length. Nevertheless, the Ebola nano-VLP remained larger than typical viruses and GP in the native conformation was present on the surface of the nanoVLP. Reduction in size of the VLP facilitated their purification by membrane chromatography, which is more easily adapted to large-scale production than a sucrose gradient method. The resulting product was also more uniform in size, although differences in morphology between spherical and filamentous fragments remained. Further advancements will be necessary to bring our laboratory-scale method to cGMP scale and meet all FDA criteria for product licensure. 
We have also presented assays for in vitro testing of GP conformational integrity in the context of VLP, the presence and relative population of filaments, and the concentration of particles in filtered VLP samples. The observed correlation of the conformational ELISA with the mouse immunopotency assay may allow its use in the future as a more rapid quality-control assay for the VLP and other types of Ebola vaccines, while the concentration of particles can be measured using the rate of events observed during flow through a nanopore.

Our results indicated that the lyophilized nano-VLP preparation was highly thermostable, but further studies will be needed to determine if long-term storage of the lyophilized formulation without refrigeration is possible. Elimination of a cold chain requirement would decrease costs associated with the vaccine and greatly ease distribution to locales without reliable electricity, especially important for a tropical disease [27].

\section{Conclusions}

We developed a procedure to reduce the size of filovirus VLP, which permitted us to purify "nano-VLP" using chromatography and filtration. We found that Ebola VLP can be reduced to a more uniform and easily manipulable size range of roughly $230 \mathrm{~nm}$ diameter, while retaining GP conformational integrity and the antigenic effectiveness of the vaccine. Additionally, the nano-VLP can be lyophilized without loss of GP and VLP structure and immunogenicity. Lyophilized nano-VLP have greatly enhanced thermostability, suggesting that the creation of an Ebola VLP vaccine without a cold chain requirement is possible.

\section{Additional file}

Additional file 1: Figure S1. Quantitation of GP in VLP by ELISA. Figure S2. Nanopore measurements of VLP samples. Figure S3. SDS-PAGE comparison of Nano-VLP preparation with sucrose-gradient purified VLP. Figure S4. Electron micrographs of Nano-VLP with immunogold staining. Table S1. Survival of vaccinated mice after ma-Ebola challenge. Table S2. Survival of mice vaccinated with Nano-VLP without adjuvant.

\section{Abbreviations}

VLP: virus-like particles; GP: glycoprotein; SIOS: scanning ion occlusion sensing; PTA: phosphotungstic acid; PBS: phosphate-buffered saline.

\section{Authors' contributions}

JHC and RDS performed purification and biophysical analyses. KAOM and JTS performed mouse testing and immunological experiments. CGR performed electron microscopy. SB contributed to experimental design and analysis of results. All authors read and approved the final manuscript.

\section{Author details}

${ }^{1}$ Molecular and Translational Sciences, United States Army Medical Research Institute of Infectious Diseases, Fort Detrick, MD 21702-9211, USA. ${ }^{2}$ Pathology Division, United States Army Medical Research Institute of Infectious Diseases, Fort Detrick, MD 21702-9211, USA. ${ }^{3}$ Present Address: Janelia Farm Research Campus, Howard Hughes Medical Institute, Ashburn, VA 20147, USA.

\section{Acknowledgements}

We thank Dr. David Hone for helpful suggestions, Dr. John Dye for antibodies used in this study, Dr. Andres Salazar of Oncovir for the poly-ICLC (Hiltonol), Steven Kern for statistics and Kathy Kuehl for EM sample preparation. Opinions, interpretations, conclusions, and recommendations are those of the author and are not necessarily endorsed by the U.S. Army. Funding was provided by the Joint Science and Technology Office Defense Threat Reduction Agency (JSTO-DTRA) \#CBM.VAXV.03.11.RD.009 and the Joint Project Management Office of Medical Countermeasure Systems (JPM-MCS) \#B.11 and B.14.

\section{Compliance with ethical guidelines}

\section{Competing interests}

A U.S. patent application is being pursued for the nano-VLP method. Sina Bavari is also an inventor on U.S. patent 7,682,618: "Generation of virus-like particles and use as panfilovirus vaccine," owned by the U.S. Army Medical Research and Materiel Command.

Received: 6 April 2015 Accepted: 2 July 2015

Published online: 15 July 2015

\section{References}

1. Feldmann H, Jones S, Klenk HD, Schnittler HJ (2003) Ebola virus: from discovery to vaccine. Nat Rev Immunol 3:677-685

2. Beniac DR, Melito PL, Devarennes SL, Hiebert SL, Rabb MJ, Lamboo LL et al (2012) The organisation of Ebola virus reveals a capacity for extensive, modular polyploidy. PLoS One 7:e29608

3. Warfield KL, Bosio CM, Welcher BC, Deal EM, Mohamadzadeh M, Schmaljohn A et al (2003) Ebola virus-like particles protect from lethal Ebola virus infection. Proc Natl Acad Sci USA 100:15889-15894

4. Warfield KL, Posten NA, Swenson DL, Olinger GG, Esposito D, Gillette WK et al (2007) Filovirus-like particles produced in insect cells: immunogenicity and protection in rodents. J Infect Dis 196(Suppl 2):S421-S429

5. Warfield KL, Swenson DL, Demmin G, Bavari S (2005) Filovirus-like particles as vaccines and discovery tools. Expert Rev Vaccines 4:429-440

6. Swenson DL, Warfield KL, Negley DL, Schmaljohn A, Aman MJ, Bavari S (2005) Virus-like particles exhibit potential as a pan-filovirus vaccine for both Ebola and Marburg viral infections. Vaccine 23:3033-3042

7. Martins KA, Warren TK, Bavari S (2013) Characterization of a putative filovirus vaccine: virus-like particles. Virol $\operatorname{Sin}$ 28:65-70

8. Warfield KL, Swenson DL, Olinger GG, Kalina WV, Aman MJ, Bavari S (2007) Ebola virus-like particle-based vaccine protects nonhuman primates against lethal Ebola virus challenge. J Infect Dis 196(Suppl 2):S430-S437

9. Warfield KL, Dye JM, Wells JB, Unfer RC, Holtsberg FW, Shulenin S et al (2015) Homologous and heterologous protection of nonhuman primates by Ebola and Sudan virus-like particles. PLoS One 10:e0118881

10. Wahl-Jensen V, Kurz SK, Hazelton PR, Schnittler HJ, Stroher U, Burton DR et al (2005) Role of Ebola virus secreted glycoproteins and virus-like particles in activation of human macrophages. J Virol 79:2413-2419

11. Bachmann MF, Jennings GT (2010) Vaccine delivery: a matter of size, geometry, kinetics and molecular patterns. Nat Rev Immunol 10:787-796

12. Zhao L, Seth A, Wibowo N, Zhao CX, Mitter N, Yu C et al (2014) Nanoparticle vaccines. Vaccine 32:327-337

13. Ungaro F, Conte C, Quaglia F, Tornesello ML, Buonaguro FM, Buonaguro L (2013) VLPs and particle strategies for cancer vaccines. Expert Rev Vaccines 12:1173-1193

14. Silva JM, Videira M, Gaspar R, Preat V, Florindo HF (2013) Immune system targeting by biodegradable nanoparticles for cancer vaccines. J Control Release 168:179-199

15. Manolova V, Flace A, Bauer M, Schwarz K, Saudan P, Bachmann MF (2008) Nanoparticles target distinct dendritic cell populations according to their size. Eur J Immunol 38:1404-1413

16. Champion JA, Mitragotri S (2009) Shape induced inhibition of phagocytosis of polymer particles. Pharm Res 26:244-249

17. Roberts GS, Yu S, Zeng Q, Chan LC, Anderson W, Colby AH et al (2012) Tunable pores for measuring concentrations of synthetic and biological nanoparticle dispersions. Biosens Bioelectron 31:17-25 
18. Bray M, Davis K, Geisbert T, Schmaljohn C, Huggins J (1998) A mouse model for evaluation of prophylaxis and therapy of Ebola hemorrhagic fever. J Infect Dis 178:651-661

19. Bavari S, Bosio CM, Wiegand E, Ruthel G, Will AB, Geisbert TW et al (2002) Lipid raft microdomains: a gateway for compartmentalized trafficking of Ebola and Marburg viruses. J Exp Med 195:593-602

20. Kozak D, Anderson W, Vogel R, Trau M (2011) Advances in Resistive Pulse Sensors: devices bridging the void between molecular and microscopic detection. Nano Today 6:531-545

21. Lee JE, Saphire EO (2009) Neutralizing ebolavirus: structural insights into the envelope glycoprotein and antibodies targeted against it. Curr Opin Struct Biol 19:408-417

22. Wilson JA, Hevey M, Bakken R, Guest S, Bray M, Schmaljohn AL et al (2000) Epitopes involved in antibody-mediated protection from Ebola virus. Science 287:1664-1666
23. Murin CD, Fusco ML, Bornholdt ZA, Qiu X, Olinger GG, Zeitlin L et al (2014) Structures of protective antibodies reveal sites of vulnerability on Ebola virus. Proc Natl Acad Sci USA 111:17182-17187

24. Martins KA, Steffens JT, van Tongeren SA, Wells JB, Bergeron AA, Dickson SP et al (2014) Toll-like receptor agonist augments virus-like particlemediated protection from Ebola virus with transient immune activation. PLoS One 9:e89735

25. Lee JE, Fusco ML, Hessell AJ, Oswald WB, Burton DR, Saphire EO (2008) Structure of the Ebola virus glycoprotein bound to an antibody from a human survivor. Nature 454:177-182

26. Hu L, Trefethen JM, Zeng Y, Yee L, Ohtake S, Lechuga-Ballesteros D et al (2011) Biophysical characterization and conformational stability of Ebola and Marburg virus-like particles. J Pharm Sci 100:5156-5173

27. Chen D, Kristensen D (2009) Opportunities and challenges of developing thermostable vaccines. Expert Rev Vaccines 8:547-557

\section{Submit your next manuscript to BioMed Central and take full advantage of:}

- Convenient online submission

- Thorough peer review

- No space constraints or color figure charges

- Immediate publication on acceptance

- Inclusion in PubMed, CAS, Scopus and Google Scholar

- Research which is freely available for redistribution

Submit your manuscript at 